\title{
Impact of Fe powder sintering and soldering in production of porous heating surface on flow boiling heat transfer in minichannels
}

\author{
Wojciech Depczyński ${ }^{1}$, Artur Piasecki ${ }^{2}$, Magdalena Piasecka ${ }^{1,{ }^{*}}$ and Kinga Strąk $^{1}$ \\ ${ }^{1}$ Kielce University of Technology, Faculty of Mechatronics and Mechanical Engineering, Al. 1000-lecia P.P. 7, 25-314 Kielce, \\ Poland \\ 2 contractor of the project from the Polish National Science Centre (No. DEC-2013/09/B/ST8/02825)
}

\begin{abstract}
This paper focuses on identification of the impact of porous heated surface on flow boiling heat transfer in a rectangular minichannel. The heated element for Fluorinert FC-72 was a thin plate made of Haynes-230. Infrared thermography was used to determine changes in the temperature on its outer smooth side. The porous surface in contact with the fluid in the minichannel was produced in two processes: sintering or soldering of Fe powder to the plate. The results were presented as relationships between the heat transfer coefficient and the distance from the minichannel inlet and as boiling curves. Results obtained for using a smooth heated plate at the saturated boiling region were also presented to compare. In the subcooled boiling region, at a higher heat flux, the heat transfer coefficient was slightly higher for the surface prepared via soldering. In the saturated boiling region, the local heat transfer coefficients obtained for the smooth plate surface were slightly higher than those achieved from the sintered plate surface. The porous structures formed have low thermal conductivity. This may induce noticeable thermal resistance at the diffusion bridges of the sintered structures, in particular within the saturated boiling region.
\end{abstract}

\section{Introduction}

The increase in heat flow intensity as used in electronic systems and other modern technologies, with a focus on minimizing the size of the heat exchangers at maximum heat flux, has led to the need for heat transfer intensification. One of the solutions is the use of boiling phenomena, the other - using enhanced heated surfaces produced by different methods [1-3]. Studies have been conducted on pool boiling [4-6], flow boiling [7-11] heat transfer and confined spaces as face seals $[12,13]$. Primarily passive methods are being developed for use in porous coating applications and in metal surface mechanical processing $[14,15]$.

Metal foams are a new type of material with a wide range of applications because of their excellent properties including light weight, impact energy absorption capacity, specific thermal acoustic properties and low thermal conductivity [16-18]. Open porous metallic foams have been used in heat and mass transfer applications, for instance in heat pipes, vapour chambers, and loop heat pipe elements. In the past few years, there has been a growing interest in metal foams. Both the foam structure and the pore morphology depend on the fabrication method. Ashby et al. [16] classify the metal foam production methods according to the process and the state of matter. Similar classification was presented in the paper by Davies et al. [17]. The superior thermal conductivity of copper foams is particularly important.
Porous sintered structures can also be produced by sintering small diameter wires. In the article [19] the alternative low-cost technology for fabrication of foams from metals, alloys, intermetallics, was proposed. The metal foam was formed by a typical base metal like Al, $\mathrm{Cu}$ and other [20-23].

The subject of this paper is the application of porous metal surfaces produced by soldering and sintering iron powder to the heated surface of the minichannel in flow boiling heat transfer experiments with a refrigerant flow. One of the porous surface types was produced with metal foams formed by reduction of metal oxides during sintering. The mixture was sintered in a dissociated ammonia atmosphere. Fe foam was prepared according to the method described in the Polish patent [24]. However crucial influence on the porosity has the ratio between quantity of metal oxide powder and amount of matrix metal powder, which is a basic structure of produced sinter [15]. This allows for compose of irregular cellular structures with pores open or closed. The foam material can be stacked and co-sintered with top layers to sandwich structures. The porous layers were formed by sintering technique the powder mixture and the reduction of iron powder ASC 100.29, ASC 100.24 , DISTALOY SE and iron oxide of different granulation. The second type of porous surface was produced by soldering the same iron powder to the tested surface (made of Haynes-230) according to the method

*Corresponding author: tmpmj@tu.kielce.pl 
described in the Polish patent [25].

A review of literature relating to flow boiling heat transfer in minichannels with microstructured surfaces, smooth and enhanced, was presented in [7-9]. Focusing research on microstructured surface of heat exchangers with minichannels seems interesting because these surfaces provide a potential for further heat transfer enhancement.

\section{Experimental stand and methodology}

\subsection{Experimental stand}

The experimental stand with the main loops: flow loop, a data acquisition system and a supply and control system is represented schematically in Fig. 1.

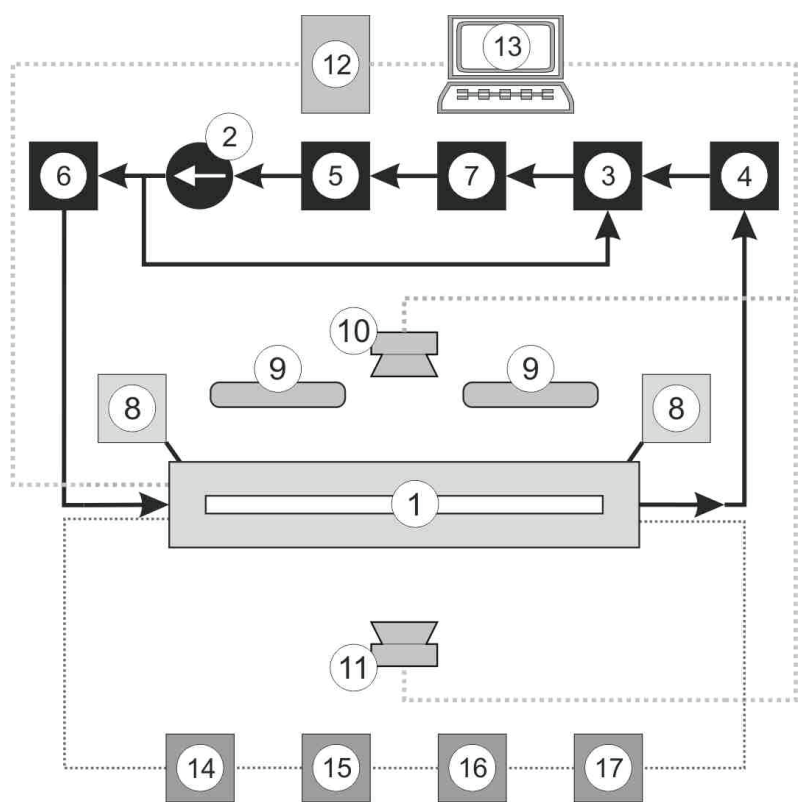

Fig. 1. The schematic diagram of the main loops and systems at the experimental setup, 1-measurement module; 2-gear pump; 3-compensating tank; 4-tube-type heat exchanger, 5-filter, 6-mass flow meter, 7-deaerator, 8-pressure transducer, 9-infrared camera; 10-fast camera, 11-high power LEDs, 12-data acquisition station, 13-computer, 14-inverter welder, 15-shunt, 16-ammeter, 17-voltmeter.

The flow loop comprises: a measurement module with a minichannel (1), a gear pump (2), a compensating tank (3), a heat exchanger (4), a filter (5), mass flow meter (6), a deaerator (7) and pressure transducers (8). The data and image acquisition system consists of: an infrared camera (11) and a fast camera (10), a lighting system (9), a data acquisition station (12) and a computer with specialized software (13). The supply and control system consists of a inverter welder (14), a shunt (15), an ammeter (16) and a voltmeter (17). The experimental setup was presented in detail in [9].

\subsection{A measurement module with a minichannel}

The study was conducted for FC-72 boiling in the test section with a rectangular, vertical and asymmetrically heated minichannel with a depth of $1.7 \mathrm{~mm}$, a width of $18 \mathrm{~mm}$ and a length of $180 \mathrm{~mm}$, Fig. 2. The heated element for fluid flowing in the minichannel was the plate made of Haynes-230 alloy with thickness of $0.45 \mathrm{~mm}$ which was enhanced on one side indirect contact with the fluid flowing in the channel. The temperature of the smooth side of the heated plate was measured by infrared camera in the central axially symmetric part of the minichannel. Thermal accuracy of the infrared camera E60 manufactured by FLIR was $\pm 1^{\circ} \mathrm{C}$ or $\pm 1 \%$ within the temperature range of $0 \div 120^{\circ} \mathrm{C}$ [11]. It was possible to observe the plate surface through a glass pane using a fast camera. K-type thermocouples and pressure transducers were installed at the inlet and outlet of the minichannel.

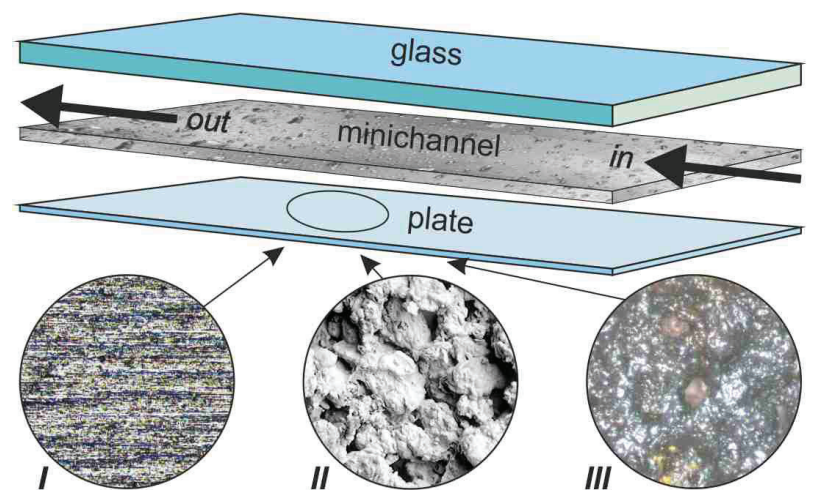

Fig. 2. The schematic diagram of a measurement module with a minichannel, I,II, II - fragment of the plate surface contacting fluid in a minichannel: I - smooth surface, II, III - the porous surfaces produced in two processes: sintering (II) and soldering (III) of Fe powder to the plate.

\subsection{The porous heated wall of the minichannel}

\subsubsection{Properties of Haynes-230 alloy}

Haynes-230 is a nickel-chromium alloy with tungsten and molybdenum additions. This alloy has excellent oxidation resistance $\left(1150^{\circ} \mathrm{C}\right)$ and superior strength at high temperature, outstanding resistance to oxidizing environments up to $1150^{\circ} \mathrm{C}$ for prolonged exposures, resistance to nitriding environments, and excellent longterm thermal stability. Haynes-230 also provides excellent service in clean and moderately-dirty environment. It is readily fabricated and formed. Haynes-230 is also mark by lower thermal expansion characteristics than most alloys, and a pronounced resistance to grain coarsening with prolonged exposure to high-temperatures [26].

\subsubsection{The tested porous surfaces}

The tested porous surfaces were produced by sintering iron powder (in the dissociated ammonia atmosphere) and by soldering the powder to the $0.45 \mathrm{~mm}$ thick plate made of Haynes-230. 
To produce the first surface type, the powder mixture was sintered in a dissociated ammonia atmosphere at $1180{ }^{\circ} \mathrm{C}$ for 45 minutes. The $\mathrm{Fe}$ foam was prepared from ASC 100.29 powder (by Höganäs company), $\mathrm{Cu}$ powder and iron oxide $\mathrm{Fe}_{2} \mathrm{O}_{3}$ (ASC100.29+12\% $\mathrm{Fe}_{2} \mathrm{O}_{3}+6 \% \mathrm{Cu}$ by weight percent). After sintering the samples situated in furnace were moved to an area where it was cooled in a protective atmosphere. Cooling took place in an average speed of about 25 degrees per minute. To determine pore size and shape from the foam specimens, the image analyser software was used. For further study there was selected the foam with an approximating $60 \%$ of porosity. The relative volume of particles of the foam was determined in accordance with the CavalieriHacquert principle [14]. The result of the porous metal foam from ASC 100.29 showed porosity approximately $60 \%$ with bulk density. The shape and chemical composition of sintered material particles affect the creation of the diffusion bridges, between which pores arise. This significant value of porosity has an important impact on the heat transfer conditions.

Fig. 3 and Fig. 4 present 3D topographies and roughness profiles for porous surfaces produced by sintering (Fig. 3) and soldering (Fig. 4) iron powder to plate being a heated wall of a minichannel.

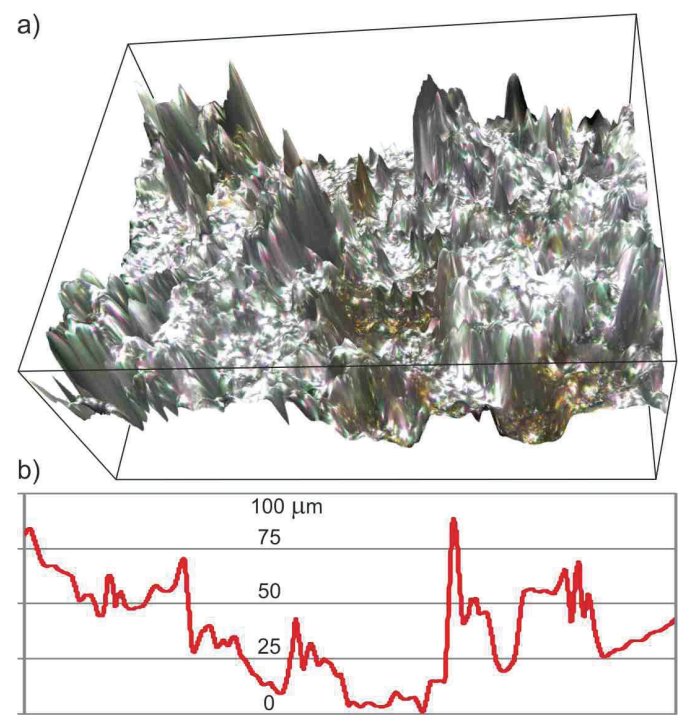

Fig. 3. Porous surface produced bysintering iron powder, a) $3 \mathrm{D}$ topography, b) roughness profile.

Soldering was carried out in according to the patent [25] application: once the surface was covered with a thin film of solder and flux, the fragmented structures of metallic material (powders) were joined by soldering to the plate. The main parameters of this porous surface are: the diameter of a solder granule - approx. $15 \div 80 \mu \mathrm{m}$ (with an average being $40 \div 65 \mu \mathrm{m}$ ); the density of the solder paste $-2990 \mathrm{~kg} / \mathrm{m}^{3}$, the thickness of the soldered layer - approx. $100 \mu \mathrm{m}$ and the maximum height of the soldered layer $-200 \mu \mathrm{m}[27]$.
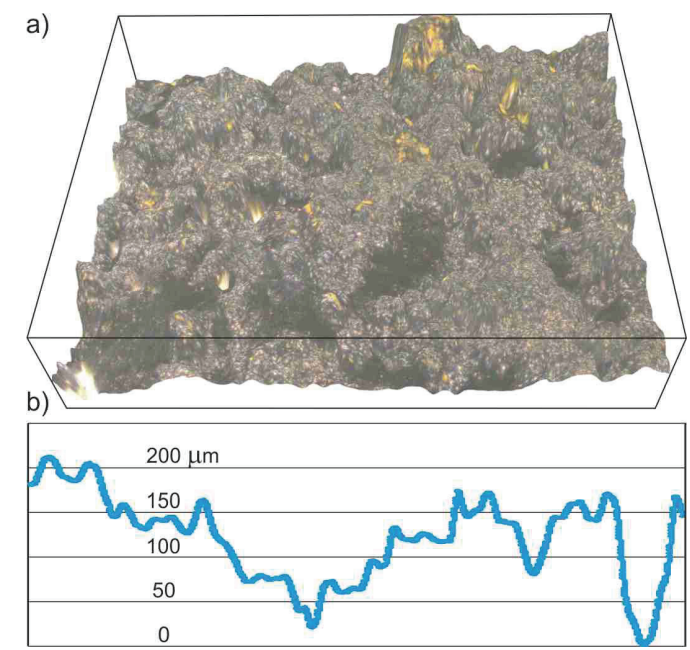

Fig. 4. Porous surface produced bysoldering iron powder, a) $3 \mathrm{D}$ topography, b) roughness profile.

\subsection{Experimental methodology}

After the desired values of the pressure and flow rate were reached, the electric power supplied to the heated plate was increased gradually to achieve an increase in the heat flux transferred to the fluid. It caused a change in the heat transfer between the plate and the fluid from single phase convection to nucleate boiling. The distribution of temperature on the heated plate was measured on the smooth side coated with a black paint layer of known emissivity [28]. Simultaneous observations of the two-phase flow structures were conducted on the opposite side of the minichannel.

Main thermal and flow parameters of the tested experimental series are listed in Table 1.

Table 1 Main thermal and flow parameters of the tested experimental series.

\begin{tabular}{|l|c|c|c|c|}
\hline \multirow{2}{*}{ Parameter } & \multicolumn{4}{|c|}{ Average or range* } \\
\cline { 2 - 5 } & \multicolumn{3}{|c|}{ surface with Fe powder/smooth } \\
\cline { 2 - 5 } & 423 & 422 & 405 & 402 \\
\hline $\begin{array}{l}\text { Mass flux } \\
{\left[\mathrm{kg} /\left(\mathrm{m}^{2} \mathrm{~s}\right)\right]}\end{array}$ & 107 & 111 & 156 & 170 \\
\hline $\begin{array}{l}\text { Absolute } \\
\text { pressure, the } \\
\text { inlet, }[\mathrm{kPa}]\end{array}$ & 104 & 102 & 144 & 173 \\
\hline $\begin{array}{l}\text { Absolute } \\
\text { pressure, the } \\
\text { outlet }[\mathrm{kPa}]\end{array}$ & 27 & 38 & 108 & 128 \\
\hline $\begin{array}{l}\text { Heat flux } \\
q_{w}\left[\mathrm{~kW} / \mathrm{m}^{2}\right]\end{array}$ & 41 & 42 & 45 & 45 \\
\hline $\begin{array}{l}\text { Inlet liquid } \\
\text { subcooling } \\
{[\mathrm{K}]}\end{array}$ & $289 \div 300$ & $291 \div 303$ & $297 \div 334$ & $297 \div 341$ \\
\hline $\begin{array}{l}\text { Fluid } \\
\text { temperature } \\
T_{l}^{*}[\mathrm{~K}]\end{array}$ & $316 \div 323$ & $319 \div 331$ & $352 \div 359$ & $359 \div 370$ \\
\hline $\begin{array}{l}\text { Heated plate } \\
\text { temperature } \\
T_{P}^{*}[\mathrm{~K}]\end{array}$ & & & & \\
\hline
\end{tabular}

$*$ range, at the inlet $\div$ at the outlet 


\section{Heat transfer coefficient determina- tion}

The local values of the heat transfer coefficient for stationary state conditions; were calculated using simple one-dimensional method. The main assumptions in this method are as follows: (i) the heat is transferred between the plate and the flowing fluid through the plate-fluid contact surface, (ii) the temperature changes in plate and fluid along the minichannel width are negligible, as are the changes on the remaining side surfaces of the plate and on the external surface of the glass, (iii) only one direction of heat flow is taken into account i.e. perpendicular to the direction of flow related to the heated plate thickness.

The resulting local heat transfer coefficients were obtained similarly as in [9, 29] from the following equation:

$$
\cdots \cdots \cdots \cdots \cdots(x)=q_{w} /\left(T_{P}(x, \delta)-T_{l}(x)-q_{w} \cdot \frac{\delta_{P}}{\lambda_{P}}\right)
$$

where $x$ - distance from the minichannel inlet, $q_{w}$ - density of the heat flux transferred from the heated plate to the fluid, $T_{p}$ - plate temperature measured by infrared thermography, $\delta_{p}-$ thickness of the plate $(0.00045 \mathrm{~m}), \lambda_{P}-$ thermal conductivity of the plate $(8.3 \mathrm{~W} /(\mathrm{m} \cdot \mathrm{K})), T_{f}$ - temperature of the fluid, assuming that $T_{f}=T_{l}$ in the subcooled boiling region and $T_{f}=T_{\text {sat }}$ in the saturated nucleate boiling region, $T_{l}-$ fluid temperature calculated from the assumption of the linear distribution of the fluid temperature along the minichannel, $T_{\text {sat }}$ - liquid saturation temperature determined from the assumption of the linear distribution of the fluid pressure along the channel. It was assumed that the saturated boiling region starts when the temperature of the heated surface is higher than the saturation temperature.

The heat transferred to the fluid in the minichannel was assumed to be equal to the difference between the heat generated by the heated plate and the heat loss to the surroundings according to the equation $[9,29]$ :

…................ $q_{w}=(I \cdot \Delta U) / A-q_{w, l o s s}$

where $I$ - current, $\Delta U$ - voltage drop, $A$ - surface area of the heated plate, $q_{w, l o s s}-$ heat loss to the surroundings.

The central part of the heated plate where the surface temperature is measured with the infrared camera (4 mm x $180 \mathrm{~mm}$ ) is not insulated. Therefore, the loss of heat to the surroundings is the greatest. It was estimated as $1.3 \%$ of the heat flux density [9].

\section{Results}

The results are represented graphically as a relationship between the heat transfer coefficient and the distance from the minichannel inlet. Separate plots were generated for the subcooled boiling region (Fig. 5) and the saturated boiling region (Fig. 6). In Fig. 6 results obtained for using a smooth heated plate in experiments was also presented to compare.

The values of the heat transfer coefficient calculated for the porous surface produced by soldering, sintering iron powder and for the smooth plate were marked with circles, diamonds, and squares, respectively.
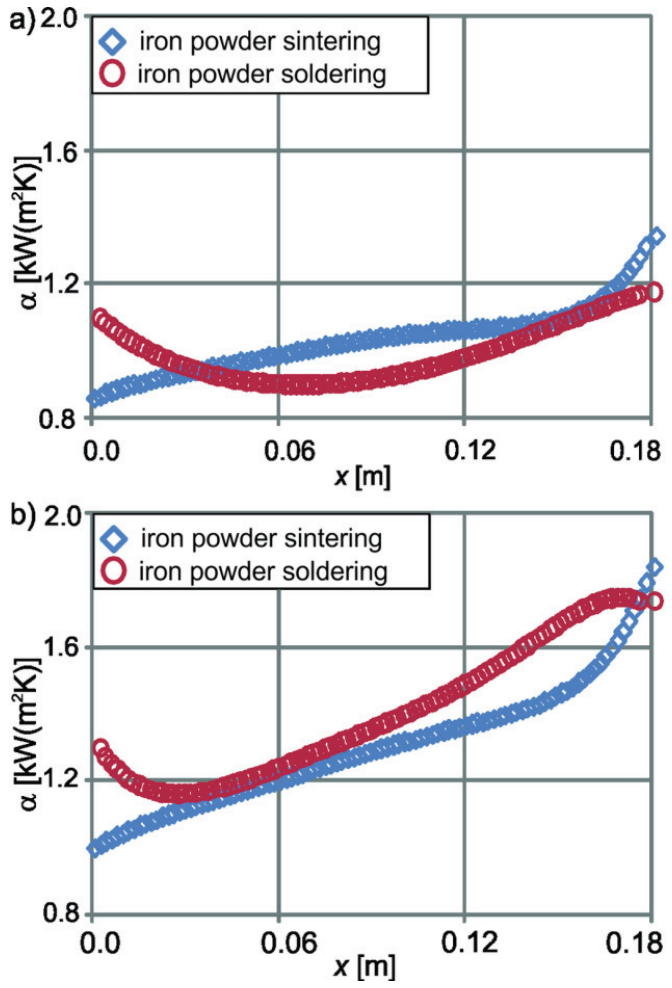

Fig. 5. Heat transfer coefficient vs. the minichannel inlet; data for the subcooled boiling region: a) $q_{w}=27 \mathrm{~kW} / \mathrm{m}^{2}$, b) $q_{w}=38 \mathrm{~kW} / \mathrm{m}^{2}$
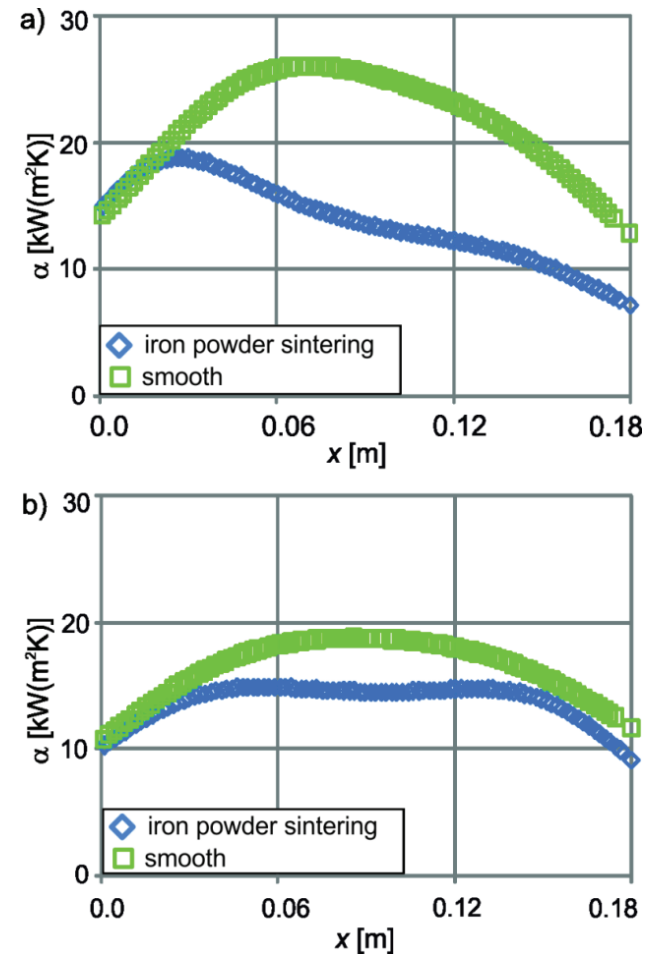

Fig. 6. Heat transfer coefficient vs. the minichannel inlet; data for the saturated boiling region, a) $q_{w}=108 \mathrm{~kW} / \mathrm{m}^{2}$, b) $q_{w}=128 \mathrm{~kW} / \mathrm{m}^{2}$. 
In the subcooled boiling region, the heat transfer coefficient was low. The local values of the heat transfer coefficient increased slightly with the increase of the distance from the minichannel inlet (Fig. 5) for two heat fluxes. At lower heat fluxes $\left(q_{w}=27 \mathrm{~kW} / \mathrm{m}^{2}\right)$, heat transfer coefficients at subcooled boiling region were slightly higher for surfaces prepared via sintering, except for the channel inlet area (Fig. 5a). At a higher heat flux $\left(q_{w}=38 \mathrm{~kW} / \mathrm{m}^{2}\right)$, local heat transfer coefficients were higher for the surface prepared via soldering (Fig. 5b).

In the saturated boiling region the heat transfer coefficient was high, with values up to over a dozen times greater (Fig. 6) than those obtained for the subcooled boiling region (Fig. 5).

Due to lack of data (the liquid in the minichannel evaporates at the set heat fluxes), the heat transfer coefficient in the saturated boiling region for the soldered surface was not calculated. Fig. 6 shows also local heat transfer coefficients from the experiments with smooth surfaces. In the saturated boiling region, the heat transfer coefficient was increasing from the inlet up to the distance of about $1 / 3$ to $1 / 2$ of the distance from the channel inlet (depending on the surface type), then it began to decrease on the way to the channel outlet. The local heat transfer coefficients during saturated boiling from the smooth surface were slightly higher than those obtained from the sintered surface. The difference is negligible at a higher heat flux, $q_{w}=128 \mathrm{~kW} / \mathrm{m}^{2}$ (Fig. 6b).

It can be underlined that the porosity of the powderbased iron structure may produce high values of thermal resistance at diffusion bridges and a decrease in the surface wettability. Finally, the formation of vapour bubbles can be responsible for the reduction in heat transfer efficiency [27]. In the case of the surface formed by iron powder soldering, thermal resistance additionally occurs at the contact zones between the substrate and solder and between the solder and Fe powder grains. Low conductivity of the material in the diffusion bridges due to sintering may contribute to relatively low heat transfer efficiency in the saturated boiling region.

Analysis of the results suggests that small dimension of the pores in both surface types may exacerbate surface wettability during the refrigerant flow and generate vapours ,plugs" thereby inhibiting heat transfer in the minichannel. This hypothesis is confirmed by the results of pool boiling heat transfer experiments, where capillary processes play a major role in the transport of refrigerants.

Boiling curves were drawn from the data collected during tests, which involved increasing the heat flux supplied to the heated plate. Boiling curves frequently represent the relationship between the heat flux density and the difference in temperature between the heated surface and the bulk fluid in the case of flow boiling in minichannel. The boiling curves in Fig. 7 were generated for three distances from the minichannel inlet: $0.06 \mathrm{~m}$ (Fig. 7a), $0.105 \mathrm{~m}$ (Fig. 7b) and $0.12 \mathrm{~m}$ (Fig. 7c). They were plotted for the two porous surfaces and the smooth plate.
The boiling curves shown in Fig. 7 were a basis for the heat processes analysis. Upon the inflow of the subcooled liquid (section A-BI), increased heat flux density leads to the onset of boiling (BI - nucleate boiling incipience). Boiling regions start with the subcooled boiling region. The liquid is superheated in the area adjacent to the plate and subcooled in the flow core. The spontaneous nucleation results in a temperature drop on the heated surface (section BI-C). The bubbles absorb a large amount of energy transferred to the liquid and act as internal heat sinks [8]. In the boiling region that follows, the saturated boiling region, the temperature of the fluid in the core of the flow is equal to the saturation temperature. Furthermore, in the fully developed nucleate boiling region, there were temperature differences $T_{P}-T_{f}$ at high heat flux (section C-D). No significant differences in shape were observed between the boiling curves plotted for the smooth surface and for the surface enhanced by soldering iron powders.
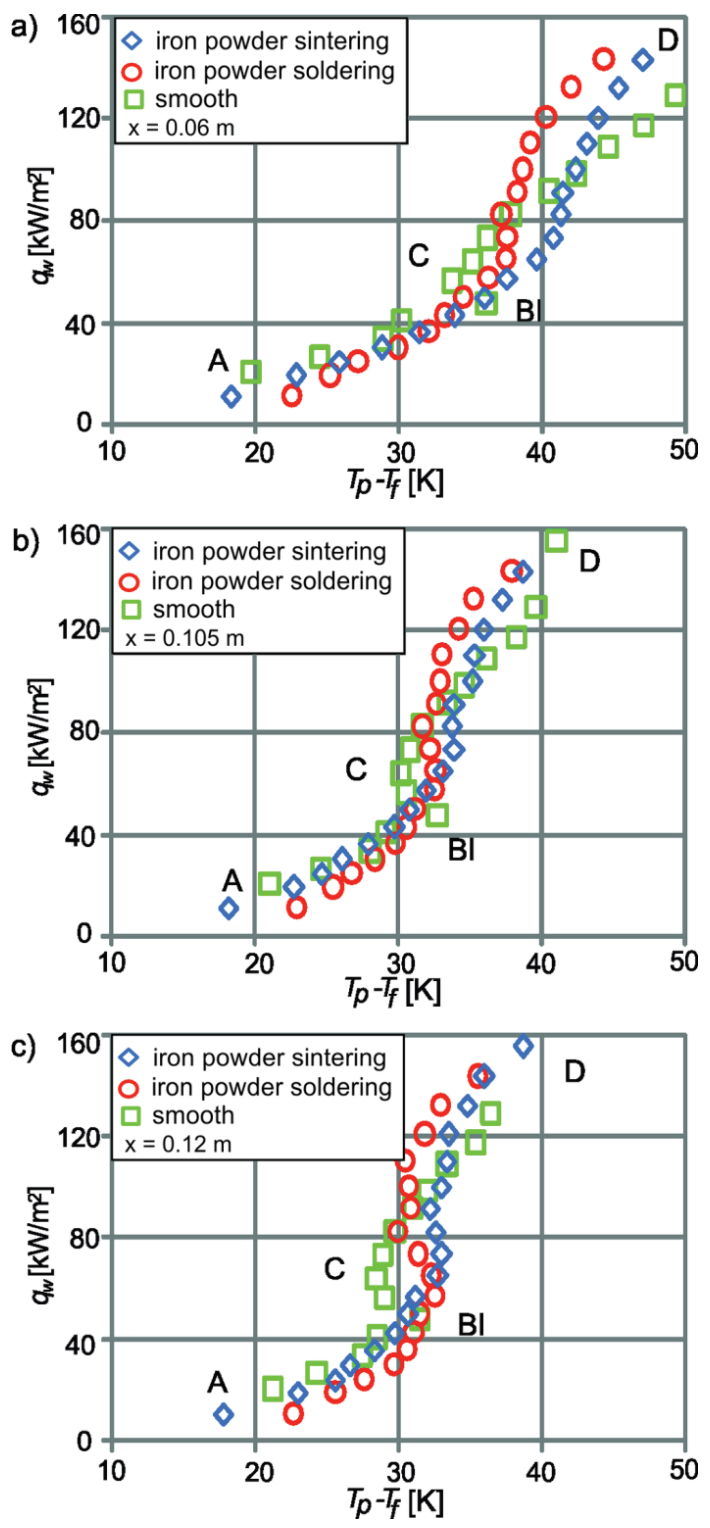

Fig. 7. Boiling curves for three distances from the minichannel inlet: a) $0.06 \mathrm{~m}$, b) $0.105 \mathrm{~m}$, c) $0.12 \mathrm{~m}$. 


\section{Conclusions}

This article focuses on identification of the impact of porous heated surface on flow boiling heat transfer in minichannel. The porous surface in contact with the fluid in the minichannel was produced in two processes: sintering or soldering of Fe powder to the plate made of Haynes-230. The results were presented as relationships between the heat transfer coefficient and the distance from the minichannel inlet and as boiling curves constructed for selected distances along the channel length. Results obtained for using a smooth heated plate in experiments was also presented to compare for the saturated boiling region.

In the subcooled boiling region, at a higher heat flux, the local heat transfer coefficients were slightly higher for the surface prepared via soldering. In the saturated boiling region, the local heat transfer coefficients obtained for the smooth plate surface were slightly higher than those achieved from the sintered plate surface.The porous structures formed from Fe powders bonded with the heated surface have low thermal conductivity. This may induce noticeable thermal resistance at the diffusion bridges of the sintered structures, in particular within the saturated boiling region.

The boiling curves were generated for three distances from the minichannel inlet. No significant differences in shape were observed between the boiling curves plotted for the smooth surface and for the surface enhanced by soldering iron powders.

\section{Acknowledgements}

The research reported herein was supported partially by a grant from the Polish National Science Centre (No. DEC2013/09/B/ST8/02825).

\section{References}

1. B. Grabas, Exp. Therm. Fluid Sci. 74, 100-109 (2016)

2. N. Radek, K. Bartkowiak, Phys. Procedia, 12 (1), 499-505 (2011)

3. N. Radek, J. Orman, Ł., L.A.D. J.I. Shalapko (Ed.), Sci. Basis Mod. Technol. Exp. Prospect., Khmelnytskyi National University, Jaremche, Ukraine, 236-245 (2011)

4. T. Orzechowski, A. Tyburczyk, K. Ziętala, Sci. Lett. Rzesz. Univ. Technol. - Mech 31, (86(2/2014))

5. R. Pastuszko, M. Piasecka, J. Phys. Conf. Ser. 395, 12137(2012)

6. R. Pastuszko, R. Kaniowski, J. Phys. Conf. Ser. 7th Eur. Therm. Conf. 25, 2019 (2016)

7. M. Piasecka, Ann. Nucl. Energy. 73, 282-293 (2014)

8. M. Piasecka, Int. J. Refrig. 56, 198-212 (2015)

9. M. Piasecka, K. Strąk, B. Maciejewska, Heat Transf. Eng. 38 (3), 332-346 (2017)
10. M. Piasecka, K. Strąk, B. Maciejewska, B. Grabas, J. Phys. Conf. Ser. 745, 3212 3(2016)

11. M. Piasecka, K. Strąk, B. Grabas, Arch. Metall. Mater. 62 (2017) (in print)

12. S. Blasiak, A. V. Zahorulko, Tribol. Int. 94, 126-137 (2016)

13. S. Blasiak, Int. J. Heat Mass Transf. 81, 90-102 (2015)

14. W. Depczynski, R. Kazala, K. Ludwinek, K. Jedynak, Materials 9 (7), 1-12 (2016)

15. W. Depczyński, Proc. Met. 2014 23rd Int. Conf. Metall. Mater., 1219-1224 (2014)

16. M.F. Ashby, A.G. Evans, N.A. Fleck, L.J. Gibson, J.W. Hutchinson, H.N.G. Wadley, Metal Foams: A Design Guide (Buterworth-Heineman, 2000)

17. G.J. Davies, S. Zehn, J. Mater. Sci. 18, 1899-1911 (1983)

18. M.A. Suarez, I.A. Figueroa, G. Gonzales, O. LaraRodriguez, G.A. Novelo-Perlata, I. Alfonso, I.J. Calvo, J. Alloy. Andg. Agent. or Spac. Compd. 585, 318-324 (2014)

19. T.M. Wójcik, EPJ Web Conf. 2501100 (2012)

20. A.M. Parvanian, M. Sadatfar, M. Panjepour, A. Kingston, A.P. Sheppard, Mater. Des. 53, 681-690 (2014)

21. A.M. Parvanian, P. M., Mater. Des. 49, 834-841 (2013)

22. Y. Hangai, K. Zushida, H. Fuji, R. Ueji, O. Kuwazuru, N. Yosikawa, Mater. Sci. Eng. A. 585, 468-474 (2013)

23. Y. Hangai, S. Koyama, M. Hasegawa, T. Utsonomiya, Metal. Mater. Trans. A. 41A, 2184-2186 (2010)

24. W. Żórawski, R. Chatys, W. Depczyński, A method of producing porous structures, Patent of the Republic of Poland, No 199720 (2002) (in Polish)

25. M. Piasecka, A method for porous structures producing on the surface of metal products, Patent of the Republic of Poland, No 225512 (2015) (in Polish)

26. HAYNES ${ } \quad 230 \AA \quad$ alloy information http://www.haynesintl.com.

27. M. Piasecka, K. Strąk, Proc. 12th Int. Conf. Heat Transf. Fluid Mech. Thermodyn. HEFAT 2016, Torremolinos-Malaga, Spain, 34-41 (2016)

28. K. Strąk, M. Piasecka, Trans. Inst. Fluid-Flow Machinery 128, 97-118 (2015)

29. M. Piasecka, B. Maciejewska, Exp. Therm. Fluid Sci. 68, 459-467 (2015) 